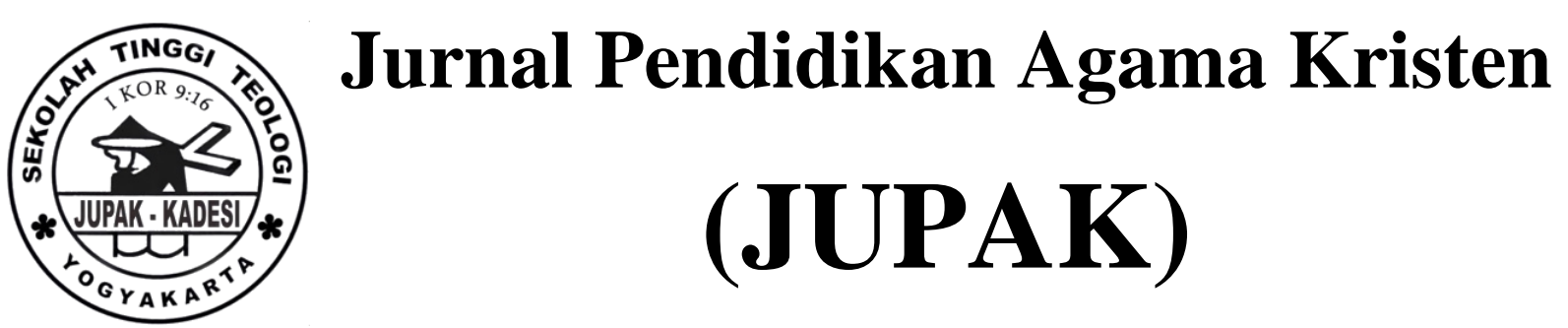

Vol. 2 No. 1 (December 2021) hlm. 01 - 12

Jurnal Pendidikan Agama Kristen (JUPAK)

e-ISSN 2774-3861

https://ejurnal.sttkadesiyogyakarta.ac.id/index.php/jupak

p-ISSN 2774-6399

\title{
https://doi.org/10.52489/jupak.v2i1.40
}

\section{Relevansi Transformational Leadership Di Lembaga Pendidikan Kristen}

\author{
Maria Titik Windarwati ${ }^{1{ }^{*}}$, Junio Richson Sirait ${ }^{2)}$, Hestyn Natal Istinatun ${ }^{3)}$, \\ Tamba Parulian ${ }^{4)}$, Emeliana ${ }^{5)}$ \\ )*Sekolah Tinggi Teologi Kadesi Boger, karnamaria@gmail.com.
}

\section{Recommended Citation}

Turabian $8^{\text {th }}$ edition (full note)

Maria Titik Windarwati et al., "Relevansi Transformational Leadership Di Lembaga Pendidikan Kristen." Jurnal Pendidikan Agama Kristen (JUPAK) 2, no 1 (December 03, 2021): 1, accessed December 8, 2021, https://ejurnal.sttkadesiyogyakarta.ac.id/index.php/jupak/article/view/40.

American Psychological Association $7^{\text {th }}$ edition

(Windarwati, 2021, p.1)

\begin{tabular}{|l|l|l|}
\hline Received: 22 August 2021 & Accepted: 05 October 2021 & Published: 03 December 2021 \\
\hline
\end{tabular}

This Article is brought to you for free and open access by Sekolah Tinggi Teologi KADESI Yogyakarta. It has been accepted for inclusion in Christian Perspectives in Education by an authorized editor of Jurnal Pendidikan Agama Kristen (JUPAK).

For more information, please contact juniorichson1995@gmail.com 


\begin{abstract}
Transformational leadership is a leadership model that is still relevant to use today. All Christian educational institutions require this pattern to develop quality in every implementation of the civitas academical. This paper aims to examine the relevance of transformation leadership patterns in Christian educational institutions through literature studies. The method in this research uses literature studies with descriptive analysis techniques. Through this study concluded that transformational leadership patterns are very relevant to be applied. Through this study, concluded that transformational leadership is very relevant to implemented in educational institutions. Transformational leadership has a role important in the achievement of the quality of education in Christian educational institutions.
\end{abstract}

Keywords: Transformational Leadership, Christian Education.

\begin{abstract}
Abstrak
Transformational Leadership merupakan model kepemimpinan yang masih relevan untuk digunakan sampai saat ini. Semua lembaga Pendidikan Kristen memerlukan model tersebut untuk menumbuh kembangkan kualitas dalam setiap pelaksanaan civitas akademika. Tulisan ini bertujuan untuk mengkaji relevansi Transformational Leadership di lembaga pendidikan Kristen melalui studi kepustakaan. Metode dalam penelitian ini menggunakan studi pustaka dengan teknik analisis deskriptif. Melalui kajian ini disimpulkan bahwa Transformational Leadership sangatlah relevan untuk diimplementasikan di lembaga pendidikan. Transformational Leadership memiliki peran penting dalam pencapaian kualitas pendidikan di lembaga pendidikan Kristen. Transformational Leadership berperan pada kepribadian dan kinerja seorang pemimpin dan tim, yang berpengaruh pada komitmen kerja, yang meningkatkan kualitas kinerja.
\end{abstract}

Kata-kata kunci: Kepemimpinan Transformational, Pendidikan Kristen.

\title{
PENDAHULUAN
}

Kepemimpinan adalah peranan dari pemimpin yang memiliki sifat universal, karena kepemimpinan hadir, ada dan selalu dibutuhkan dalam setiap organisasi. Kepemimpinan juga dapat dikatakan sebuah tindakan pemimpin yang menunjukkan adanya hubungan yang erat antara pemimpin dengan patner kerjanya. Kepemimpinan mempunyai fungsi sebagai penggerak dan koordinator dari sumber daya manusia, sumber daya alam, semua dana dan sarana yang disiapkan oleh sekumpulan manusia yang berorganisasi. Pemimpin harus membuat hubungan yang saling mempengaruhi antara dirinya dengan patner kerjanya (Ariani, 2010, p. 172). Jadi, keberadaan pemimpin di dalam sebuah organisasi tidaklah dapat dipisahkan karena keduanya saling membutuhkan. Banyaknya perdebatan mengenai definisi kepemimpinan akhirnya melahirkan pendapat bahwa kepemimpinan tidak hanya berkaitan dengan siapa yang menggunakan pengaruh tetapi juga menyangkut tentang jenis pengaruh yang digunakan dan bagaimana hasilnya. Beberapa peneliti membatasi definisi kepemimpinan dengan penggunaan pengaruh yang menghasilkan komitmen yang tinggi 
terhadap para patner kerja yang awalnya berlawanan dan ketidakrelaan untuk mematuhi pemimpin (2021, pp. 239-240).

Seseorang pemimpin yang menggunakan kontrol atas penghargaan dan hukuman dengan tujuan memanipulasi atau memaksa para patner kerja tidaklah dapat dikatakan seseorang yang benar-benar "memimpin" karena hal tersebut merupakan tindakan yang tidak etis, yang menyalahgunakan kekuasaan. Tindakan yang demikian akan mendapatkan kosekuensi dari organisasi yang menaunginya dan Tuhan (Ristiono \& Sirait, 2021, p. 193). Pemimpin haruslah menjalankan kepemimpinannya dengan efektif yang sesuai dengan kebutuhan dan karakteristik di dalam organisasi yang menaunginya (Nurmayanti et al., 2021, p. 22). Kent dan Chelladural (2001, pp. 135-159), dalam penelitiannya tentang Transformational Leadership mengatakan bahwa gaya dan sikap kepemimpinan adalah salah satu yang mempengaruhi kepuasan kerja dan komitmen organisasi, maka kepemimpinan memiliki peran penting dalam menentukan komitmen patner kerja di setiap organisasi. Tinggi rendahnya kepuasan, komitmen, dan kinerja dapat dilihat dari baik atau tidaknya gaya dan sikap para pemimpin. Komitmen adalah bagian dari ukuran kekuatan indentifikasi pemimpin yang memiliki tujuan dan nilai organisasi dan keterlibatan didalamnya. Transformational Leadership menjadi sangat menarik untuk diteliti karena memiliki pengaruh besar terhadap kepuasan kerja dan komitmen organisasi. Hal ini menjadi model kepemimpinan yang sangat tepat untuk diterapkan di dunia lembaga pendidikan Kristen pada masa kini. Gea dan Darmawan (2021, p. 10) dalam penelitiannya tentang humanisme dan pendidikan Agama Kristen menyimpulkan bahwa humanisme membawa manusia kepada pengidolaan diri sendiri yaitu tindakan yang tidak suka mencontoh orang lain, bahkan Tuhan. Situasi tersebut merupakan bahaya yang cukup besar terhadap kemajuan dan kualitas lembaga pendidikan Kristen. Maka, lembaga pendidikan kristen membutuhkan sosok yang dapat menciptakan pengaruh positif kepada tenaga pengajar maupun pelajar. Transformational Leadership menjadi solusi untuk menolong organisasi pendidikan Kristen dalam mewujudnyatakan pengaruh tersebut. Ratnaningtyas (2021, p. 31), dalam penelitiannya bersama temantemannya menyatakan "Transformational leadership has a significant positive effect on work productivity”, dengan demikian Transformational leadership menjadi model kepemimpinan yang cukup menarik untuk diteliti peranannya pada lembaga pendidikan Kristen. Artikel ini akan membahas mengenai kajian praktis yang menunjukan relevansi Transformational Leadership dari lembaga pendidikan Kristen yang sampai saat ini belum disentuh oleh para peneliti sebelumnya. Transformational Leadership kemungkinan besar dapat menciptakan 
sosok pemimpin yang memberikan pengaruh positif kepada setiap orang yang menjadi patner kerjanya di lembaga pendidikan. Model kepemimpinan tersebut sangat cocok untuk diterapkan dalam kepemimpinan di lembaga pendidikan agama Kristen karena memiliki potensi dalam membawa setiap patner kerja kepada tujuan yang sama.

\section{METODE}

Metode dalam penelitian ini menggunakan studi pustaka dengan menggunakan bukubuku, artikel dan hasil penelitian terdahulu yang mendukung tema penelitian ini seperti literatur-literatur tentang transformational leadership, kepemimpinan dan yang mencakup model-model kepemipinan. Studi pustaka ini akan mengintepretasikan data secara deskripsi analisis. Menurut Masrukhin tahapan dimulai dengan melakukan reduksi data dari sumber kepustakaan, kemudian mengorganisasi dan memaparkan data, melakukan verifikasi kemudian diakhiri dengan menyimpukan data (sirojudin, 2019, p. 104). Sasaran yang akan dicapai yaitu menguraikan transformational leadership dengan menekankan relevasinya pada kepemimpinan masa kini.

\section{HASIL DAN PEMBAHASAN}

\section{Transformational Leadership}

Konsep transformational leadership awalnya diperkenalkan oleh James MacGregor Burns pada tahun 1979, dalam bukunya yang berjudul Leadership. Istilah tersebut menunjukkan kepada tindakan mengubah bentuk proses kepemimpinan antara pemimpin dengan patner kerjanya yang saling membantu untuk menuju ke tingkat yang lebih tinggi yang didasari oleh semangat dan motivasi (Burns \& Publishers, 1978, pp. 71-73). Melalui kekuatan visi dan kepribadian, kepemimpinan transformational mampu menginspirasi patner kerja untuk mengubah harapan, persepsi dan motivasi menuju tujuan yang sama. Pemimpin harus membuat visi yang terencana dengan baik dan terukur (Wahyuni, 2021, p. 119). Transformational leadership adalah gaya kepemimpinan yang dapat menciptakan kondisi yang saling memotivasi antara pemimpin dengan semua patner kerja. Pemimpin dapat membuat para patner kerja menjadi lebih baik dan memiliki rasa kepercayaan yang tinggi kepada kepemimpinnya.

Bernard Bass (1985, pp. 86-87), dalam upayanya mengembangkan teori transformational leadership memberikan empat komponen. Pertama, stimulasi intelektualtransformational, menantang status quo dan mendorong kreatifitas patner sekerja. Kedua, pertimbangan individual seperti melibatkan, menawarkan dukungan dan dorongan kepada 
patner kerja, bebas berbagi ide, dan pemimpin memberikan pengakuan secara langsung kepada bawahan sebagai kontribusi unik. Ketiga, motivasi inspirasional memiliki visi yang mampu mengartikulasikan patner kerja. Keempat, Pengaruh ideal yang berfungsi sebagai model panutan peran agar lebih percaya dan menghormati serta meniru pemimpinnya yang diinternalisasi dalam cita-cita, sehingga transformational dapat meningkatkan motivasi, semangat dan kinerja para bawahan melalui berbagai mekanisme supaya dapat menyelaraskan bawahan dengan tugas-tugas untuk meningkatkan kinerja.

Dengan demikian, model transformational leadership sangat terlihat menekankan motivasi intrinsik dan perkembangan positif pada semua bawahannya. Model kepemimpinan ini lebih merepresentasikan pandangan kepemimpinan yang menarik dibanding kepemimpinan transaksional yang mementingkan proses pertukaran peran-peran sosial. Transformational leadership lebih memungkinkan untuk diaplikasikan dalam lembaga pendidikan saat ini yang semakin kompleks yang dimana para patner kerja tidaklah hanya menginginkan pemimpin yang dapat menginspirasi dalam membantunya melalui perkerjaannya tetapi pemimpin juga menginginkan setiap patner kerja harus memiliki loyalitas atau memperlihatkan kinerja yang baik (B. M. Bass \& Riggio, 2006, p. 11). Melalui model transformational leadership ada tiga bagian yang dapat membuat pemimpin menjadi berhasil dalam mengupayakan setiap patner kerjanya agar dapat memiliki loyalitas atau memperlihatkan kinerja yang baik. Berikut tiga bagian tersebut:

Pertama, kharisma digambarkan sebagai komponen paling penting dalam konsep kepemimpinan transformational. Sedikit yang bisa dipakai untuk menggambarkan seorang pemimpin kharismatik, dimana di dalamnya termuat perasaan cinta dari anak buah, bahkan bawahan merasa percaya diri dan saling mempercayai di bawah seorang pemimpin yang kharismatik, bawahan menerima pemimpinnya sebagai model yang ingin ditirunya, setiap saat tumbuh antusiasme kerja anak buah, mampu membuat anak buah bekerja lebih keras dan lebih lama dengan senang hati. Skala kharisma kepemimpinan transformastional mendeskripsikan tingkat sejauh mana pemimpin menciptakan antusiasme anak buah, mampu membedakan hal-hal yang benar-benar penting. Membangkitkan perasaan mengemban misi terhadap organisasi, melalui kharisma pemimpin mengilhami loyalitas dan ketekunan menanamkan kebanggaan dan kesetiaan serta membangkitkan rasa hormat.

Kedua, konsideran individual maksudnya di bawah kepemimpinan tranformasional, penyamarataan perbedaan antar individu tidak memperoleh tempatnya. Seorang pemimpin transformational akan memperhatikan faktor-faktor individual sebagaimana tidak boleh 
disamaratakan, karena adanya perbedaan kepentingan dan pengembangan diri yang berbeda satu sama lain.

Ketiga, stimulus intelektual maksudnya dalam transformational leadership seorang pemimpin akan melakukan stimulasi-stimulasi intelektual. Elemen kepemimpinan ini dapat dilihat antara lain dalam kemampuan seseorang pemimpin dalam menciptakan, menginterpretasikan dan mengelaborasi simbol-simbol yang muncul dalam kehidupan, mengajar bawahan untuk berfikir dengan cara-cara yang baru. Pemimpin diharapkan mampu membuka peluang walaupun dalam situasi sulit (Rumbiak et al., 2021, p. 35). Pendeknya bawahan dikondisikan pada situasi untuk selalu bertanya pada diri sendiri dan membandingkannya dengan asumsi yang berkembang di masyarakat, yang untuk selanjutnya mengembangkan kemampuan pemecahan masalah secara bebas (Triatna \& Komariah, 2010, p. 78).

\section{Faktor-faktor yang Mempengaruhi Kepemimpinan Transformational}

Keberhasilan dalam kepemimpinan tidaklah terlepas dari faktor-faktor yang memiliki pengaruh besar terhadap keberhasilan seorang pemimpin. Faktor-faktor tersebut memiliki pengaruh besar di setiap proses perjalanan dan pengambilan keputusan dalam setiap situasi yang tidak memungkinkan untuk mencapai kepada kesuksesan. Berikut ini kedua tokoh penting serta pemahamannya tentang faktor-faktor tersebut yaitu:

\begin{tabular}{|c|l|l|}
\hline \multirow{2}{*}{ No. } & \multicolumn{2}{|c|}{\begin{tabular}{c}
\multicolumn{2}{|c|}{ Taktor-faktor yang Mempengaruhi Kepemimpinan } \\
Transformational
\end{tabular}} \\
\cline { 2 - 3 } & $\begin{array}{l}\text { Stephen P. Robbin dan Timothy } \\
\text { A. Judge (2013, pp. 416-418). }\end{array}$ & $\begin{array}{l}\text { Jerald Greenberg dan Robert } \\
\text { A. Baron (2008, pp. 518-519). }\end{array}$ \\
\hline $\mathbf{1 .}$ & Pengaruh ideal & Karisma \\
\hline 2. & Motivasi & $\begin{array}{l}\text { Memiliki visi dan misi yang kuat } \\
\text { terhadap organisasi. }\end{array}$ \\
\hline 3. & Inspirasi & Stimulasi intelektual \\
\hline 4. & Stimulasi intelektual & Pertimbangan individu \\
\hline $\mathbf{5 .}$ & Pertimbangan individu & Motivasi inspirasi \\
\hline
\end{tabular}

\section{Keunggulan Kepemimpinan Transformational}

Kunggulan dari konsep kepemimpinan adalah bagian yang sangat penting untuk dimengerti oleh banyak orang dalam mempersiapkan dirinya menjadi seorang pemimpin. Keunggulan dapat dimiliki melalui kompetensi diri yang seringkali tidak dapat diusahakan. 
Namun, kebanyakan kompetensi dari seseorang pemimpin adalah hasil dari jerih lelahnya dalam proses menanggapai posisi kompetensi tersebut. Keunggulan dari kepemimpinan transformational adalah menciptakan perubahan. Perubahan merupakan salah satu bagian yang sangat penting dan harus dimiliki dalam setiap perjalanan seseorang pemimpin karena ia harus dapat mengubah semua arah perjalanan kinerja patnernya menjadi searah dengan jalan yang telah ditetapkan. Transformational leadership adalah solusi dari gerakan yang dapat menciptakan perubahan dalam setiap perjalanan kepemimpinan. Kreitner dan Kinicki (2008, pp. 66-68) berpendapat bahwa transformational leadership akan mengubah bawahannya dengan menciptakan perubahan tujuan, nilai, keyakinan dan aspirasi. Keempat bagian ini menjadi penting untuk diperhatikan karena dengan berubahnya hal tersebut maka tercipta keserasian arah jalan antara pemimpin dengan patner kerja. Melalui transformational leadership seorang pemimpin dapat menciptakan suasana baru (perubahan) yang dapat membuat banyak patner kerja merasakan kepercayaan, kekaguman, kesetiaan dan penghormatan terhadap pemimpin. Patner kerja termotivasi untuk dapat melakukan secara maksimal segala sesuatu yang dipercayakan sehingga hasilnya lebih dari yang diharapkan. Terdapat tiga keunggulan dari kepemimpinan transformational yang dapat mengubah dan memotivasi para patner kerja yaitu:

\section{Kesadaran akan Pentingnya Tugas}

Kesadaran akan pentingnya setiap tugas yang diberikan menjadi bagian yang sangat penting dan nyata pada kualitas partner kerja yang sedang dipimpin oleh pemimpin di lembaga pendidikan agama Kristen. Partner kerja haruslah sadar bahwa target yang akan dicapai bukan seperti yang diinginkan oleh dirinya sendiri melainkan seperti yang diinginkan oleh organisasi yang menaunginya. Seringkali kegagalan dalam mencapai misi organisasi banyak disebabkan oleh karena ketidakselarasan misi organisasi dengan orang-orang yang berada di dalamnya. Maka, sosok pemimpin harus menjadi pribadi yang dapat membuat kesadaran yang penuh (memotivasi dan menginspirasi) kepada setiap partner kerja supaya dapat menjalankan segala sesuatu sesuai dengan jalan yang diinginkan oleh lembaga pendidikan, sehingga hasil yang didapat seperti yang telah direncanakan (sirojudin, 2019, p. 105). 


\section{Memprioritas Kepentingan Tim atau Organisasi}

Memprioritaskan kepentingan tim merupakan tindakan yang tepat pada saat seseorang melakukan segala sesuatu yang dipercayakan. Melalui hal tersebut mereka akan mencapai tujuan yang telah dibuat oleh organisasi sehingga keberhasilan akan tercapai secara bersamasama karena setiap partner kerja dapat mengerjakan sesuai dengan pembagian kerja yang jikalau semua dapat menyelesaikan dengan baik maka dapat tercipta tujuan yang telah dibuat oleh organisasi dan inilah keberhasilan yang sesungguhnya. Oleh sebab itu pemimpin lembaga pendidikan agama Kristen diharapkan mampu untuk mendorong para partner kerjanya untuk mendahulukan kepentingan tim (sirojudin, 2019, p. 106). Kepemimpinan Transformational adalah wujud dari kepemimpinan yang dapat menolong setiap pemimpin untuk tidak mementingkan kepentingan diri sendiri melainkan kepentingan tim yang orientasinya kepada keberhasilan lembaga pendidikan bukan personal.

\section{Mengaktifkan Kebutuhan}

Kebutuhan adalah bagian yang harus diutamakan dari pada banyaknya keinginan yang dapat menggagalkan misi organisasi. Melalui tindakan memprioritaskan kebutuhan maka setiap organisasi dapat mencapai standar keberhasilan yang telah ditetapkan sebelumnya. Mengaktifkan kebutuhan menjadi bagian yang sangat penting karena faktor situasi seperti banyaknya orang yang datang berkerja dalam organisasi hanya memiliki tujuan untuk memenuhi keinginan pribadi bukan organisasi yang menaunginya, oleh sebab itu maka perlulah peranan dari seorang pemimpin untuk mengaktifkan kebutuhan organisasi kepada semua orang yang dipimpinnya. Pemimpin harus dapat menggerakkan semua partner kerja dengan mengembangkan prilaku, nilai dan sikap baru (Marbun, 2020, p. 78). Transformational leadership menjadi jawaban terhadap permasalahan yang dialami oleh semua pemimpin di lembaga pendidikan Kristen dalam mewujudnyatakan hal tersebut. Transformational leadership akan menolong para pemimpin dalam menjalani proses perjalanan kepemimpinannya. Melalui kharisma dan intelektual yang dimiliki oleh pemimpin, transformational leadership akan menolongnya untuk mengaktifkan kebutuhan organisasi dalam pikiran dan perasaan orang-orang yang berada di dalamnya.

\section{Lembaga Pendidikan Kristen}

Lembaga pendidikan Kristen merupakan bentuk organisasi yang memiliki tujuan yang mulia yaitu membantu dari generasi ke generasi menjadi pribadi yang excellent. Mata 
pelajaran Pendidikan Agama Kristen menjadi sangat penting karena memiliki peranan dalam membangun iman (Sunarko, 2021, p. 98). Tentunya organisasi ini memiliki perbedaan yang jauh dengan organisasi lainnya. Hal ini terlihat jelas pada orientasi di setiap lembaga yang pada dasarnya banyak didirikan dengan harapan mendapatkan keuntungan. Berbeda dengan lembaga pendidikan yang memiliki harapan untuk membentuk generasi menjadi semakin baik. Pada lembaga pendidikan kesuksesan tidak hanya ditentukan oleh pimpinan, melainkan juga ditentukan oleh pengajar, staf, pelajar, dan proses civitas lembaga itu sendiri. Namun, dalam situasi tertentu seperti pandemi ini, banyak lembaga tidak dapat berbuat apa-apa mengenai tindakan yang seharusnya dilakukan. Pandemi membuat perekonomian berjalan tidak baik (Sutanto, 2021, p. 36). Pemimpin menjadi sosok yang sangat diharapkan oleh semua partner kerjanya untuk melakukan transformasi terhadap situasi buruk yang sudah datang. Melalui transformasi tersebut diharapkan organisasi dan para karyawan mendapatkan kehidupan yang semakin membaik sehingga semua pekerja tetap fokus dengan target yang telah ditentukan.

\section{Relevansi Transformational Leadership di Lembaga Pendidikan Kristen}

Berdasarkan pembahasan di atas maka dapat disimpulkan bahwa transformational leadership adalah perilaku individu atau seorang pemimpin yang berupaya mengubah, mengarahkan, dan mengembangkan nilai-nilai yang ada kepada orang-orang yang berada di dalam organisasi agar terciptanya hubungan yang baik antara pemimpin dan partner kerja demi mewujudkan cita-cita organisasi di masa depan dengan indikator kharisma, konsiderasi individual, pengaruh ideal, inspirasi yang memotivasi, dan stimulus intelektual. Bagian ini menjadi penting untuk ada pada lembaga pendidikan Kristen. Supaya apapun masalah yang datang, lembaga ini tetap berjalan dengan baik bahkan dapat menolong lembaga lainnya.

Berdasarkan temuan yang di dapat, transformational leadership sangatlah relevan terhadap komitmen pada anggota yang berada di lembaga pendidikan, maka diperlukan adanya perbaikan khusus pada kepribadian pemimpin dan partner kerja. Adapun upaya-upaya yang perlu ditingkatkan sehubungan dengan hal tersebut adalah mengutamakan layanan pengajar sebagai tenaga profesional, peningkatan kualitas diri pengajar sehubungan dengan kemampuan dan karir, meningkatkan pengembangan keilmuan, dan meningkatkan kompetensi kepribadian.

Adapun indikator yang dapat dilakukan untuk meningkatkan kinerja pengajar adalah adanya upaya yang dilakukan untuk meningkatkan kinerja pengajar seperti perlakuan adil 
dalam pelayanan pekerjaan, pembenahan dan peningkatan upah, dan perhatian terhadap kesejahteraan pengajar.

Memperbaiki kepribadian pengajar juga memiliki pengaruh besar terhadap peningkatan kinerja. Kepribadian merupakan ciri dan sifat yang khas dan mewakili sikap atau tabiat pengajar, mencakup pola-pola pemikiran dan perasaan, konsep diri, perangai, dan mentalitas yang umumnya sejalan dengan kebiasaan umum dimasa depan. Hal itu dapat memperkuat kepribadian pengajar yang berpengaruh terhadap peningkatan kinerja pengajar.

Adapun yang harus diperhatikan untuk mencapai kemaksimalan dalam penerapan transformational leadership yaitu selalu meningkatkan kompetensi, meningkatkan upah dan gaji, meningkatkan pelatihan dan sarana, meningkatkan pendidikan dan kenaikan jabatan, memperluas pengetahuan dan keterampilan, memberikan penghargaan dan sangsi hukuman.

\section{REKOMENDASI PENGEMBANGAN PENELITIAN}

Transformational leadership adalah model kepemimpinan yang cukup menarik untuk diteliti dalam berbagai perspektif yang tentunya harus sesuai dengan konteks pada lokus penelitian seperti, melihat seberapa besar pengaruh transformational leadership pada lembaga yang diteliti, atau melihat masalah-masalah yang cukup dominan pada saat penerapannya dan memberikan solusi terhadap masalah tersebut. Penulis sangat berharap kiranya penelitian ini menjadi salah satu bagian yang dapat memberikan sumbangsih terhadap perubahan kepemimpinan dan menjadi rujukan bagi peneliti-peneliti berikutnya.

\section{KESIMPULAN}

Berdasarkan analisis relevansi yang ada pada pembahasan transformational leadership dan lembaga pendidikan, maka ditemukan bahwa model kepemimpinan transformational leadership masih sangat relevan untuk diterapkan pada masa kini. Semakin tinggi kepribadian yang baik pada pemimpin dan partner kerja, maka akan semakin tinggi juga komitmen pada organisasi. Semakin besar kinerja pemimpin dan partner kerja maka akan semakin kuat komitmen dalam melaksanakan tugas yang telah dipercayakan. Kepribadian dan kinerja secara tim sangatlah berpengaruh terhadap komitmen pada organisasi, karena secara empiris kepribadian yang stabil akan dapat meningkatkan kinerja dan akan berpengaruh terhadap komitmennya pada lembaga pendidikan Kristen. Transformational Leadership berperan pada kepribadian dan kinerja seorang pemimpin dan tim, yang berpengaruh pada komitmen kerja, yang meningkatkan kualitas kinerja. 


\section{BIODATA}

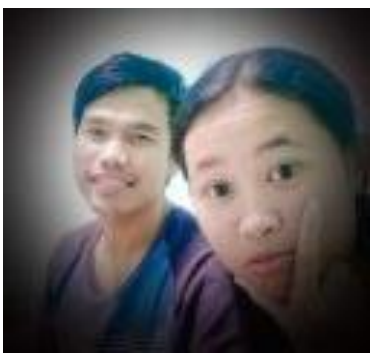

My name is Junio Richson Sirait. After graduated from Sekolah Tinggi Teologi KADESI Yogyakarta in 2018 and continued my study at Sekolah Tinggi Teologi Kadesi Yogyakarta. Now I still work at Researching and publishing Sekolah Tinggi Teologi Kadesi Yogyakarta.

\section{Junio Richson Sirait}

Surel: juniorichson1995@gmail.com

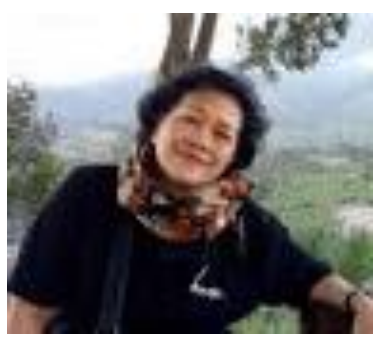

Hestyn Natal Istinatun adalah dosen tetap di Sekolah Tinggi Teologi Kadesi Yogyakarta. Dia juga mengajar di salah satu Universitas ternama yaitu UGM (Universitas Gajah Mada). Melalui pengajaran dan tulisan diktatnya, ia telah mempersiapkan banyak generasi muda menjadi generasi kritis terhadap perkembangan jaman.

\section{Hestyn Natal Istinatun}

Surel: hestynistinatun@gmail.com

\section{REFERENSI}

Ariani, D. W. (2010). Hubungan Pertukaran Pemimpin-Pengikut, Kepuasan Kerja Dan Komitmen Organisasional. JBTI : Jurnal Bisnis : Teori Dan Implementasi, 1(2), 158 176. https://journal.umy.ac.id/index.php/bti/article/view/2415

Bass, B. (1985). Leadership And Performance Beyond Expectations.

Bass, B. M., \& Riggio, R. E. (2006). Transformational Leadership. Taylor $\backslash \&$ Francis. https://books.google.co.id/books?id=2WsJSw6wa6cC

Burns, J. M. G., \& Publishers, H. I\& R. (1978). Leadership. Harper $\ \&$ Row. https://books.google.co.id/books?id=DeztAAAAMAAJ

Gea, L. D., \& Darmawan, I. P. A. (2021). Tantangan Humanisme Bagi Pendidikan Agama Kristen Abad 21 Dan Tanggap Teologisnya. Jurnal Shanan, 5(1), 1-14. https://doi.org/10.33541/shanan.v5i1.2621

Greenberg, J., \& Baron, R. A. (2008). Behavior in organizations. Pearson Prentice Hall.

Kent, A., \& Chelladurai, P. (2001). Perceived Transformational Leadership, Organizational Commitment, and Citizenship Behavior: A Case Study in Intercollegiate Athletics. Journal of Sport Management, 15(2), 135-159. https://doi.org/10.1123/jsm.15.2.135

Kreitner, R., \& Kinicki, A. (2008). Organizational behavior. McGraw-Hill/Irwin. 
Marbun, P. (2020). Pemimpin Transformatif dalam Pendidikan Kristen. MAGNUM OPUS: Jurnal Teologi Dan Kepemimpinan Kristen, 1(2), 72-87. https://doi.org/10.52220/MAGNUM.V1I2.47

Nurmayanti, P., Suryawati, E., Firzal, Y., Ramaiyanti, S., \& Maulida, Y. (2021). Model Konseptual Kepemimpinan, Gender, Dan Diversitas. Jurnal EL-RIYASAH, 12(1), 1-25. http://ejournal.uin-suska.ac.id/index.php/elriyasah/article/view/13151

Ratnaningtyas, H., Handaru, A. W., \& Eryanto, H. (2021). Transformational Leadership and Work Motivation on Work Productivity Mediated by Work Engagement: An Introductory Analysis. The International Journal of Social Sciences World, 3(1), 25-32. https://doi.org/https://doi.org/10.5281/zenodo.5131374

Ristiono, Y. B., \& Sirait, J. R. (2021). Refleksi Teologi Kovenan Berdasarkan Kejadian 1-3 dan Implikasinya bagi Kehidupan Orang Percaya Masa Kini. Ejournal.Sttkb.Ac.Id, 1(1), 186-200. https://ejournal.sttkb.ac.id/index.php/kadesibogor/article/view/9

Robbins, S. P., \& Judge, T. A. (2013). Organizational behavior (15, global ed.). In Boston ua: Pearson.

Rumbiak, W., Pendidikan, W. T.-J. M., \& 2021, U. (2021). ANALISIS KEBIJAKAN PENDIDIKAN DALAM PENYIAPAN SARANA DAN PRASARANA PADA PERENCANAAN PEMBELAJARAN TATAP MUKA DI SMA KRISTEN. Jurnal Manajemen Pendidikan, 10(01), 28-36.

http://ejournal.uki.ac.id/index.php/jmp/article/view/3264

Sirojudin, Didin. (2019). Signifikansi Kepemimpinan Tranformational. JoEMS (Journal of Education and Management Studies), 2(2), 103-108.

https://ojs.unwaha.ac.id/index.php/joems/article/view/117

Sunarko, A. S. (2021). Fungsi Keluarga dalam Persepektif Alkitab sebagai Basis Pendidikan Agama Kristen. Jurnal Pendidikan Agama Kristen (JUPAK), 2(1), 79-93. https://doi.org/10.52489/jupak.v2i1.15

Sutanto, T. S. A. (2021). IMAN DAN PEMULIHAN PEREKONOMIAN DI MASA PANDEMI. GENEVA: Jurnal Teologi Dan Misi, 3(1), 35-47. https://sttiaa.ac.id/ejournal/index.php/geneva/article/view/38

Triatna, A. K., \& Komariah, A. (2010). Visionary Leadership Menuju Sekolah Efektif. Jakarta: Bumi Aksara.

Wahyuni, S. (2021). Pemimpin Gereja Visioner Pelaku Perubahan. Jurnal Teologi (JUTEOLOG), 1(2), 187-200. https://doi.org/10.52489/JUTEOLOG.V2I1.27

Widodo, Z. D., Wijiastuti, S., \& Darmaningrum, K. (2021). Pengaruh Kepemimpinan Transformasional Terhadap Kinerja Karyawan Yang Dimediasi Oleh Kepercayaan Organisasional dan Komitmen Afektif di PT Arpeni Pratama Ocean Line Tbk. Cabang Jepara. JENIUS (Jurnal Ilmiah Manajemen Sumber Daya Manusia), 5(1), 238-248. https://doi.org/10.32493/JJSDM.V5I1.13157 